\title{
El Acceso a la INFormación PÚBlica: DEBATES Y DESAFÍOS EN LA INTERSECCIÓN ENTRE LA REFLEXIÓN ACADÉMICA, LA GESTIÓN PÚBLICA Y EL EJERCICIO SOCIAL DE UN DERECHO DEMOCRATIZADOR
}

"Acceso a la Información Pública: diálogos entre lo jurídico, lo administrativo y lo comunicacional" constituye un apartado especial que surgió como iniciativa del proyecto bienal de investigación Comunicando la Transparencia: dispositivos técnicos y conceptuales para la apropiación ciudadana de las políticas de acceso a la información pública alojado en el Universidad Nacional de Cuyo, y que encontró una muy positiva recepción por parte de Millcayac - Revista digital en Ciencias Sociales ${ }^{1}$.

Es así que el dossier que integra este número es resultado, entonces, de un gratificante recorrido colaborativo que permitió acceder a un sólido espacio de divulgación científica, para presentar algunos debates en torno a una temática de fuerte actualidad, interés social y demanda de gestión pública; y al mismo tiempo generar una apertura de la línea editorial de la publicación a nuevas temáticas y enfoques.

El acceso a la información pública en Argentina ha cobrado un importante protagonismo en la agenda pública vigente, sobre todo si se piensa a partir del juego de demandas y articulaciones que se establece entre Estado y Sociedad, expresada esta tanto en torno a organizaciones de la sociedad civil, como en el ejercicio de ciudadanía autónoma para parte de quienes habitan una jurisdicción.

En este sentido, cada vez con mayor asiduidad y en distintas formas desde la Sociedad se incrementa el requerimiento para conocer distintos aspectos de la cosa pública como mecanismo de control de transparencia en las gestiones, la búsqueda de canales de participación, y la obtención de datos para accionar cotidiano de las personas.

Al analizar las distintas políticas públicas y las dinámicas de gestión que en torno al acceso a la información pública diseñan y aplican los Estados, se puede afirmar que el escenario actual se caracteriza por una heterogeneidad que alcanza distintos planos: legislaciones, enfoques jurídicos, procedimientos administrativos y dinámicas de construcción comunicacional para la presentación de la información que presentan una variedad de experiencias en la que conviven respuestas intuitivas frente a la demanda, con procesos de clara profesionalización en los cuales se consolidan esas políticas públicas como políticas de Estado, como se puede

${ }^{1}$ El presente Dossier fue coordinado por el Mgter. Daniel Gonzalez, el Dr. Julio Aguirre, la Mgter. Karina Jaureguiberry y la Mgter. Soledad Zumer (Facultad de Ciencias Políticas y Sociales. Universidad Nacional de Cuyo. Argentina). 
observar en el Índice de Acceso a la Información Pública en las Provincias Argentinas publicado por el Banco Mundial en 2018.

Un caso testigo de esto es la legislación comparada donde se encuentran marcos normativos que presentan un alcance mínimo y acotado a los Poderes Ejecutivos hasta experiencias como la de la provincia de Mendoza que incluye a todos los poderes y organismos del Estado e invita a adherir a los municipios, con una autoridad de aplicación con carácter de órgano extra poder con acuerdo del Senado local.

Esta dispersión que se observa en el campo de la administración pública se replica a su vez en la consideración social respecto del carácter de aquello que es alcanzado por la caracterización de información pública, y que da lugar a tensiones entre lo que la normativa define y establece con carácter de público, y los procedimientos y formas que regula para el otorgamiento de datos; y lo que cada ciudadano y ciudadana entiende como público (e incluso desearía que sea etiquetado como público). De nuevo, el análisis de experiencias diversas muestra que en muchas ocasiones se presentan, bajo el paraguas de información pública, requerimientos que corresponden a otros trámites administrativos de carácter personal y privado y que implica 2 cuestiones:

por un lado, exige un tiempo de gestión por parte de los funcionarios a trámites que no corresponden; y por otro, en muchos casos entran en juego aspectos vinculados a información protegida al tratarse justamente de aspectos personales $\mathrm{o}$ procesos judiciales (Ética Pública Mendoza, 2021, p.3).

Otro aspecto que se evidencia en el uso social del acceso a la Información Pública es la no correlación de demandas que se produce entre el conjunto de pedidos que provienen desde solicitantes que ostentan distintos tipos de representación, como por ej. funcionarios y agentes públicos o periodistas; y las temáticas que despiertan interés en el grueso de la ciudadanía.

Como muestra resulta útil el Informe del Trimestre 3/2020 publicado por la Auditoría de Ética Pública de Mendoza, en el cual se afirma:

Respecto del recorte temático, se mantiene la tipología de los pedidos realizados a estos organismos durante los 2 trimestres anteriores: a) modos de acceso a planes de vivienda, b) solicitudes de deudas 
hipotecarias, impositivas o de derechos de riego, c) datos técnicos para ser aplicados en distintos tipos de trabajos, muchos de ellos relacionados a CONICET y equipos de investigación de Universidades Nacionales; d) información vinculada a lo catastral. Esto permite deducir un fuerte interés ciudadano en temáticas que la afectan de forma cotidiana en su condición de sujetos individuales o familiares. Este aspecto resulta de interés cuando se analiza la variable de caracterización de solicitantes. En el relevamiento de datos, se identifican 33 pedidos $(10,11 \%)$ realizados por sujetos $u$ organismos que poseen representación institucional pública, sindical o vinculados al ámbito periodístico; y que por su propia actividad poseen otras canales institucionales para acceder a la información. El principal dato que surge aquí es que ninguno de ellos es dirigido al organismo más solicitado, lo cual permite interpretar una asimetría entre los intereses de estos sectores, y los de la población global (2021, p.11).

En este breve recorrido y caracterización, no puede soslayarse el efecto que la pandemia de COVID-19 tuvo en el ámbito que nos interesa. Situaciones como las declaraciones de emergencias sanitarias y económicas; el registro diario del avance de la enfermedad; el interés social sobre el proceso de vacunación; o la proliferación de condiciones de sobre información en convivencia con una fuerte presencia de noticias falsas (fake news) que dieron lugar a plantear la noción de infodemia, tornaron de gran importancia que desde los Estados se avance en generar condiciones para simplificar el acceso a datos oficiales para intentar llevar certidumbre en una etapa caracterizada por lo imprevisible.

Es en esta diversidad de enfoques y perspectivas que el presente dossier viene a proponer visiones y debates para intentar enriquecer el campo, y avanzar en las necesarias articulaciones entre los desarrollos académicos en diálogo con las miradas provenientes desde la sociedad y con el ejercicio concreto de la gestión pública. Y por ello, se celebra también la presencia de artículos elaborados por autores y autoras que junto a la investigación científica cumplan roles activos en la función pública, como los casos de María Gracia Andía, titular del Órgano Garante de Acceso a la Información Pública en la Ciudad Autónoma de Buenos Aires; y Daniela García, diputada provincial en la Provincia de Mendoza y una de las autoras del proyecto que derivó en la ley 9070, de Acceso a la Información Pública. 
En este número, el reconocido Oscar Oszlak (Centro de Estudios de Estado y Sociedad) interpela al Poder Judicial al preguntarse, en formato de conferencia, ¿quién tiene la llave para abrir a la Justicia? y promover así la transparencia, la colaboración, la rendición de cuentas y la participación ciudadana en ese ámbito.

Luego, Andía (Facultad de Derecho de la Universidad de San Andrés) junto a Inés Colombato (Facultad de Derecho de la Universidad de Buenos Aires) abordan la histórica tensión entre el acceso a la información pública y la protección de datos personales, y toman como caso testigo el desarrollo del plan de vacunación contra el COVID-19 en Argentina.

Por su parte, citada García (Facultad de Ciencias Políticas y Sociales, UNCuyo), junto a Julián Bertranou (Facultad de Ciencias Políticas y Sociales. Universidad Nacional de Cuyo/ Universidad Nacional de San Martín) avanzan en un estudio de legislación comparada entre el régimen nacional y la normativa de Mendoza.

Luego, María Candela Grec (Universidad Nacional de Quilmes) coloca su mirada en la implementación de políticas públicas sobre transparencia, participación ciudadana y colaboración en los gobiernos locales, a partir de analizar la experiencia en ejecución en el municipio de Ciudad de Mendoza respecto de su Plataforma de Estado Abierto.

Por último, Ana Beatriz Lemos da Costa, Luma Poletti Dutra y Fernando Oliveira Paulino, de la faculdade de Comunicação da Universidade de Brasília, aportan una mirada sobre el interés latinoamericano en la temática al indagar sobre el Derecho de Acceso a la Información en Brasil y México, en particular al observar el proceso de creación de normativa específica en esos países.

Mgter. Daniel Gonzalez Facultad de Ciencias Políticas y Sociales. Universidad Nacional de Cuyo. Argentina

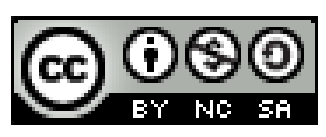

Licencia Creative Commons Atribución-No Comercial-Compartir Igual 4.o Internacional 